\title{
LEGIBILITY
}

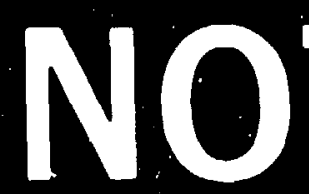

$\checkmark$

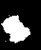

A major purpose of the Technical Information Center is to provide the broadest dissemination possible of information contained in DOE's Research and Development Reports to business, industry, the academic community, and federal, state and local governments.

Although a small portion of this report is not reproducible, it is being made available to expedite the availability of information on the research discussed herein. 
LA-UR - $88-2888$

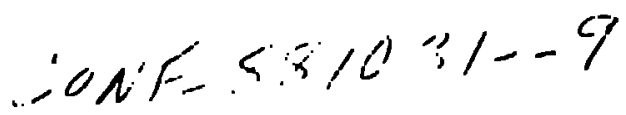

TITLE TECHNOLOGY AND PHYSICS IMPLICATIONS OF OSCILLAT ING-FiELD CURRENT DRIVE IN REVERSED-FIELD PINCHES

AUTHOR(S). BATHKE, Charles G. KRAKOWSKI, Robert $A$. SCHOENBERG, Kurt F.

\title{
IDS'I.AIMH:R
}

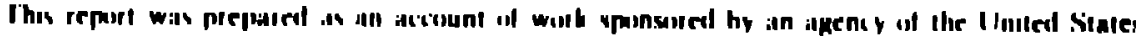

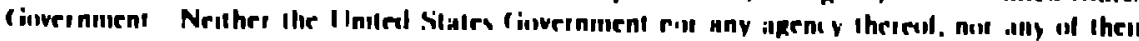

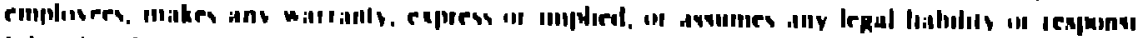

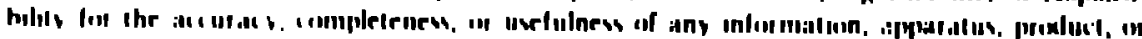

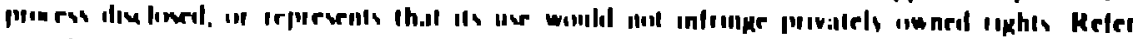

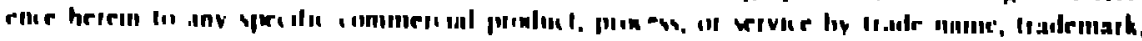

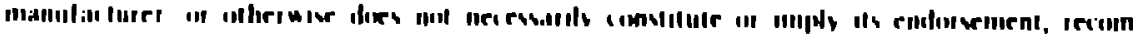

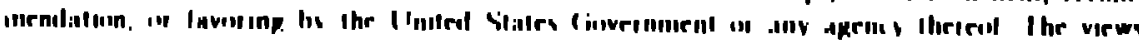

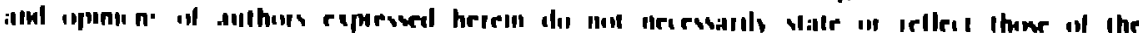

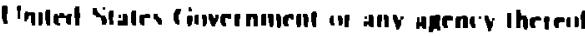




\section{TECHNOLOGY AND PHYSICS IMPLICATIONS OF OSCILLATING-FIELD CURRENT DRIVE IN REVERSED.FIELD PINCHES ${ }^{\dagger}$}

C. G Bathke, R. A Krakowaki, and K F. Schoenberg

Los Alamos National Laboratory, F641 Los Alamos, NM 87e45

\section{ABSTRACT}

The property of reversed-field pinches (RFPs) to relax to near-minimum-energy state is the basis of oncillating-field curient drive (OFCD), wherein plasma current is driven by modulating in quadratuie the external toroidal and poloidal magnetic fields. Coupled plasms/circuit OFCD simulations of RFP, ranging from present experiments (ZT. $P$ and $Z T-40 M$ ) io the resctor (TITAN) indicate that the drive frequency and the amplitude of the plasmscurrent ascillations decrease and the "wall-plug" currentdrive efliciency increases with decreased plasma resistance so that reinimum frequencies $(\sim 25 \mathrm{~Hz})$ end plasme-current amplitudes $(\sim 1.6 \%)$ and maximum efliciencies $(\sim 0.3 \mathrm{~A} / \mathrm{W})$ se entained in the reactor regime Methode for minimizing the reactive powers and for optimizing the current-drive efficiency for OFCD in RFP, hove been identified

\section{INTPODUCTION}

The prowerty of reversed-field pinches (RFPs) to relax to a neu-minimumenergy itose ${ }^{1,2}$ may be exploited 10 drive a ready-atate plasma current ${ }^{3,4}$ Relaxation processes related to turbulence and or resistive instebilities can convert toroidal magnetic energy into polordal magnetic energy and vce versa, while maintaining the near-minimum energy RFP otate that is characterized by large on-axis toroidal field (comparable to the edge-plasma potoidal finid; which decreases 10 - low roverned value outside the plasme. During oxillating-field current drive (OFCD). the coroidai and potoidal marnetic fields at the plasme surface are modulated in quadrature (i.e, $\pi / 2$ phase shift) Thoer monlines relexption proceses rectify the externally. drivan modulations into a net ready-state plasme cirrient and have been obmeived experimentally to produce $.5 \%$ increase in poloidal flux" in ratatively cold (resutive) plasma Although inconcluaive, these postive indicstions werrent en exemsnation of OFCD to determine the reector potential and to sesess the physics and technoloey requirements The full spectrum of RFP, conging from present experiments (ZT. $P^{A}$ und $7 T-40 M^{4}$ ) ehrough devices under constevction $\left(Z T H^{\top}\right)$ to the reactor (TITAN") ere enalyred to eatimate the requireswent, In developing OF $\mathrm{CO}$ :echrolocy

1 Wort wpporied by US DOE

\section{Plasma and CiRcuit models"}

\section{A. Plasma Model}

The OFCD power flow is derived herein from energy balance ${ }^{4}$ rather than helicity balance. 'A power balance imposed at the plasme aurface. Adinition of the plasma internal magnetic enercy, and o positive Faraday' L Low $\left(l_{a}=d \phi^{\dagger}, d t\right)$ yield the following expression for the plasma toroidal loop voltage, $V_{\text {. }}$

$V_{\phi}=I_{\phi} R_{p}+\left[L_{p}+\frac{\theta}{2} \frac{d L_{p}}{d \Theta}\right] I_{\phi}+\left[\frac{1-F}{\epsilon \Theta}-\frac{e \Theta^{2}}{2 L_{0}} \frac{d L_{p}}{d_{\theta}}\right] V_{\theta}$

where 1 .e ore the toroidal and poloidal voltages applied to the plasma. $R$, is the plasma resistance, $L_{p}$ is the plasma internal inductence (not including vacuum toroidal flux $), F=B_{*}\left(r_{p}\right) /\left(B_{a}\right)$ is the reversal porameter. $A=$ $B_{\theta}\left(r_{p}\right) /\left\langle B_{\alpha}\right\rangle$ is the pinch parameter, $\left\langle B_{\phi}\right\rangle-\phi / \pi r_{p}^{2}$ is an average toroidal freld vithin the plasma minor radius, $r_{p}$. and $L_{o}=\mu_{n} r_{p}^{3} / 2 R_{T}$ is the vacuum toroidal inductance.

Oscillaticns of 1.. in proper phase can cive a net lime overaged current, with the time-everaced toroidal voltage aqual to zero (. . no net change in poloidal flux) The axcillation period, $T=f^{-1}$, muat be longer than the plasma ralaxation time to permit the rectificetion of the external. field modulations into ateady-state current but much ahorter than the time for the resistive decay of the current (the plasmo $L / R$ time). One possible plasma relaxstion process that increases the poloital flux and is used for the basse of this discussion is a class of $m-1$ MHD cearing modes" which ore described by the Kadomt rev reconnection model $\bullet .10$ The procest that decresses the polordal flux is a double reconnection" remonsible for the "dynamo eflect "in the RFP which mainteins the lerge on-axis toroudal field The characteriatic growth time. ${ }_{T} T$. for thase tearing instabilities is determined numerically ${ }^{0} 11$ to be $T, \quad l(K)$. A where , A

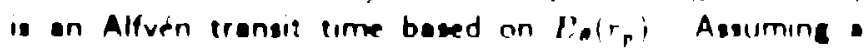
remistive MHO scaling ( $\left.e, r_{T} \times S^{1 / 2}\right) . r_{l} \quad\left(11 T_{A} T_{A}\right)^{1 / 2}$

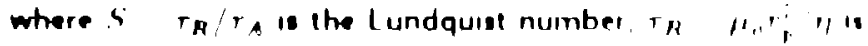
the reastive plasme current dec ay time. and "I is the plesme reselivity The conetrant on the period is $T$. TI The constrane $T$. 'th is required to ensure suffuresily amoll 
amplitude field oscillations in order to maintain toroidalfield reversal (i.e., $F<0$ ). The steady-state value of $F$ determines the tolerable difference between $T$ and $T_{R}$. For all the devices considered here, $-0.2 \leq F \leq-0.1$. and $T \leq 10^{2} T_{R}$ is needed to maintair reversal. Within these constraints * non-intrusive means to drive current using primarily the main confining coil system in a low-frequency. low-amplitude mode becomes possible for the RFP.

Solving Eq. (1) requires the $\theta$ dependency of $F$, as mell as the $\theta$ dependency of the magnetic field, $\bar{B}$. and current density, $\vec{j}$, profiles, and hence, $L_{p}$ and $R_{p}$. A circularized, one-dimensional MHD model described in Ref. 12 is used. The radial densily, temperature, and $\mu \equiv \mu_{0} \vec{j} \cdot \vec{B} / B^{2}$ profiles required as input to the MHD model are based on one-dimensional plasma simulations for FTF's (fusion tert facility) and TITAN (commercial restctor). Normalized density and temperature profiles of the form $\left[1-\left(r / r_{p}\right)^{3}\right]$ and a flat normalized $\mu$-profile of the form $\left[1-\left(r / r_{p}\right)^{0}\right]_{\text {are }}$ assumed for ZT.P and ZT.H. Given a potoidal bets, $\beta_{0}$, and $I_{\phi}$, the MHO model determines the corresponding value of $F$ and $\theta$. An $F-\theta$ curve is then generated by varying $I_{\phi}$. The $\theta$ dependency of $L_{p}$ and $R_{p}$ also is obtained by the oppropriate integration of the MHD-model generated $\bar{B}$ and $\vec{j}$ profiles. respectively.

The algorithm for identifying steady-state solutions to Eq. (1) fixes the amplitude of a sinusoidal toroidal-flux furiction, $\delta \phi / \phi_{0}$. and iterales spon the amplitude of anusoidal toroidal-voltecte function. $\delta V_{\phi} / l_{\phi}$. until the plasme current becomes periodic, i.e., $I_{a}(t)=I_{0}(t+T)$. The coroidal-flux and voltage functions are in phase to produce the maximum current drive. An initial guess for $\delta l_{\alpha} / l_{\alpha n}$ is obtained from the constraint that the time-averaged helicity is constant which yields the following condition on the amplitudes of the coroidal-flux and voltace uscillations: $\left(\phi \phi / \phi_{n}\right)\left(\delta V_{\phi} / V_{\phi n}\right)=$ -2 . The plasma current is reset to the desired value at the beginning of each simuiation period. The time scale also is edjusted to enaure that the mean current during - period aquals the current at the bezinning of the period

\section{B. Crecult Model}

An exwement of OFCD efliciency requires the modeling of the circuit eternent, external to the plasme, as well as the plasmo. in order to eccount for all power diasipation. The power flow is shown renematically in Fis 1 . The governing matrix circuit equation is written as follows

$$
\vec{L} \overrightarrow{d f}+\overrightarrow{\vec{R}} \ddot{I}-\vec{l} \text {. }
$$

where $I$ and $l$ ' are column vectors representing the currents and woltages. reapectively. $\overline{\vec{R}}$ is - diegonal matrix of resistances, and $\dot{Z}$, is the inductence matrix The inductences in Eq (2) we time independent, becouse il consists only of the external circuit-element inductences and the plasma external inductance: the plasma iniernal inductence appears in Eq. (1). Circuit equations are derived for poloidal and toroidal current pathe and are labeled $\theta$ and $\phi$. respectively. eccording to the current direction.

A ahell model is used to determine the inductances and the resistances used in the matrices. Standard wire and toroidal ahell formulae't for currents in the toroidal and poloidal direction, respectively, are used for the self-inductances. The mutual inductance between two elements is taken as the omaller ceff-inductence of the two elements. The resistance of a circuit element is determined by assuming the current flows in the smaller of either the current penetration skir. depth or the annular thickness of the conducting shell

The circuit elements simulated are the plasma. first wall or liner, the toroidal-field (TF) coils, the ohmic heating $(\mathrm{OH})$ coils, the blanket or shell, \& primery equilibrium-tield (EF) coil set. and an optional secondary equilibrium-field (trim) coil set (Fig. 1), which dissipate most of the power The current vector $I$ of Eq. (?). then, has components corresponding to each circuit element listed above. The plasma current in the toroidal-circuit is the $I_{\text {, solution }}$ to Eq. (1).

In solving Eqs. (1) and (2) simultoneously. the plasms resistance is taken as zero in Eq. (2), beceuse it is olready included in Eq. (1). The voliege vector of Eq (2) contains the external voltazes applied to the coils. The TFcoil voltage is determined by requiring the coroidal field at

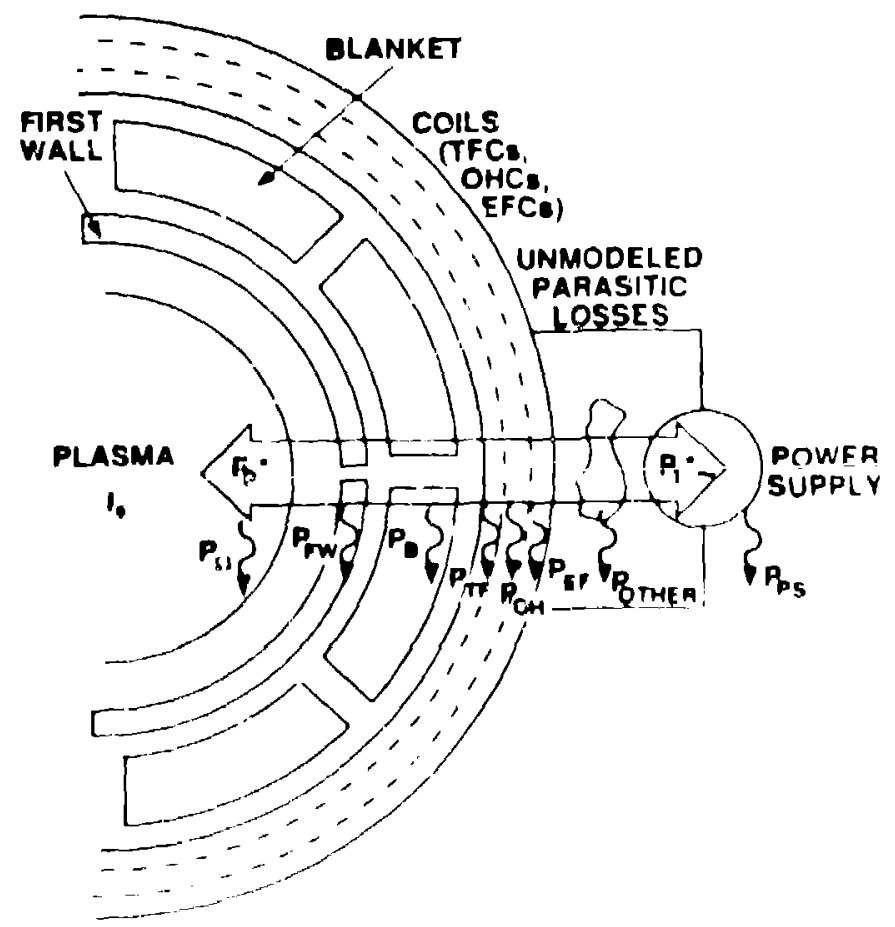

Fiquie 1. Schemstic diegram of the Of ( D powe flow 
the plasme surface be produced by all the elements with continuous poloidal current paths. The OH-coil voltege is serived from the solution for $I_{\text {f }}$ from Eq. (1). If trim coils are used, the EF-coil voltage is maintained at a constant value sorresponding to the mean equilibrium field. The voltage applied to the trim coil (the EF coil if trim coils ore not sed) is determined by requiring the trim coils to track the acillating equilibrium-field requirement of the plasme. ${ }^{13}$ For sasaive elements like the first wall (liner) the applied voltage s zero. The applied toroidal plasma voltage in Eq. (2) is $-V_{\phi}$, because $V_{\phi}$ is o voltage drop as written in Eq. (1) The applied poloidal plasma voltage, however, is $V_{0}$, because I positive Faraday's low is used.

I need to model passive elements with resistive breaks r gaps arises for simulations of shells used in presentlay experiments. which ore designed with gaps to allow renetration of magnetic fields during the current-rise phase. leactor first walls also ore simuloted with gaps to minimize nower loss. The model derived here for circuit elements with aps aimulates each passive element as on inner and outer urrent path. as is shown in Fig. 2. The current is assumed o flow in the amaller of either half of the radial build of the assive etement or a current penetration skin depth. The eff-inductance of an element with saps is the difference $f$ the seli-inductances of the inner and outer current-path lements. The mutual inductance between an element with sps and a continuous dement is the difference betwern the wnimum of the self-inductances of the inner current-path lement and the continuous element and the minimum of re self-inductances of the outur current-path element and re continuous element. The resistance of an element with sps is the oum of the resistances of the inner and outer srrent-poth elements.

he time-dependent current and voltage coitutions to Eq l) ere colved in conjunction with the $I_{p}(t)$ solution to Eq

1. The efectrical time constents of the ixternal circuits ore

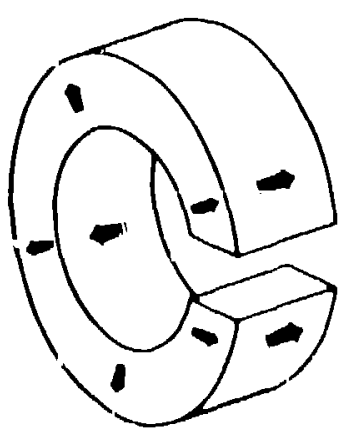

TOROIDAL

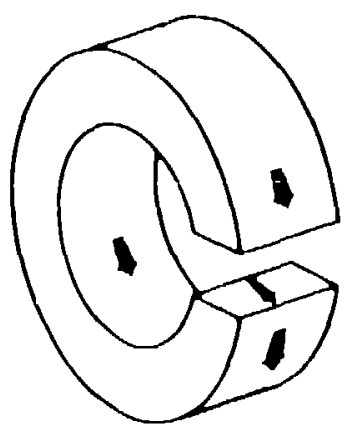

POLOIDAL bure 2. The current pathe envisioned for the passive rcuil dements with reastive breaks orthogonal to the xremponding continisous current direction eufficiently shor so that periodic colutions to Eq. (1) and (2) are obtained simulteneously. The dissipated powers and peak reactive powers of the entire system are derived from the calculated current and voltage wove forms

\section{RESULTS}

The alcorithms described in Sec. II hove been spplied to the following air-core RFPs, which span the entire epectrum of RFPs: ZT.P.' ${ }^{\circledR} T H_{1}{ }^{7}$ FTF, ${ }^{13}$ and TITAN$1^{*}$. The porametery that describe these devices are listed in Table I. The ZT-P device is a emall protolype of ZTH which is presently under construction. The FTF device is - proposed "ignition" class RFP. which in - reteady-state version could provide a neutron source for fusion technology testing." The resctor regime is represented by the iteadyrete, high neutron-wall loading (18 $\mathrm{MW} / \mathrm{m}^{2}$ ) TITAN-II deaign. The TITAN-II dexign was selected in this mtudy in order to prewerve a common TF-coil design; namely. normal-conducting Cu-alloy TF coils positioned outside of the blanket/shell are used in all the devices considered. Table I also gives parometers for the ZT-40M device, which is an iron-core machine on which OFCD experiments have been conducted. ${ }^{3}$

The shell model is illustroted in Fig. 3 for ZT-P. A shell rodius is determined by requiring the shell to opproximate the physical location of the circuit etement to be simulated. The thickness of a shell annulus is determined by requiring the shell to have the same resist ance as the circuit element simulated. A comperison of ZT-P inductences calculated with this shell model and a high recolution, multi-filementery

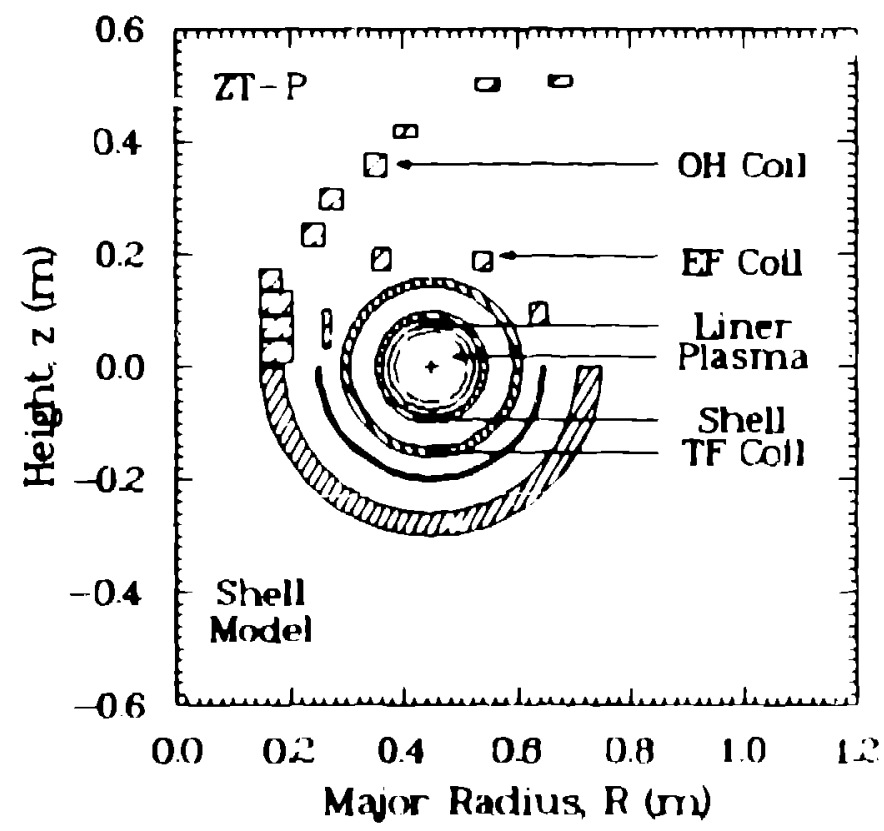

Figure 3 Cross-aectional view of ZT P above the equatorial plane and the shell model below the equatorial plane 
TABLE I. Device Par-inters and OFCD Reaults for a Spectrum of RFPs

\begin{tabular}{|c|c|c|c|c|c|}
\hline Parameter & ZT-Po & $2 T-40 M^{5}$ & $2 \mathrm{TH}^{7}$ & FTF ${ }^{13}$ & TITAN $\|^{n}$ \\
\hline Major toraidal radius, $R_{T}(m)$ & 0.45 & 1.14 & 2.40 & 1.8 & 3.90 \\
\hline Minor plasma radius, $\tau_{p}(m)$ & 0.062 & 0.18 & 0381 & 0.3 & 0.6 \\
\hline Plasma temperature, $T_{e}(\mathrm{keV})$ & 0.3 & 0.15 & 2.0 & 9.0 & 9.5 \\
\hline Poloidal beta, $\beta_{\theta}$ & 0.35 & 0.1 & 0.1 & 0.1 & 0.22 \\
\hline Effective charge. $Z_{\text {ess }}$ & 6.26 & $\sim 3$ & 3.93 & 1.69 & 1.69 \\
\hline Plasma toroidal loop woltage. $V_{\Delta}(V)$ & $35(0.34)^{(a)}$ & 50. & 7.0 & 2.3 & 1.6 \\
\hline Liner with or without gaps & withoul & without & without (with) & with & with \\
\hline Plasma resistive time constant, $T_{R}(g)$ & $0.0026(0.26)^{(\bullet)}$ & 0.002 & 1.73 & 20.3 & 109 \\
\hline Oscittation period, $T=f^{-1}(\mathrm{~ms})$ & 0.2 & 0.5 & 5. & 16.7 & 40 \\
\hline Tearing time constant, $r_{T}(\mathrm{~ms})$ & $0.068(0.68)^{(a)}$ & 0.2 & 1.95 & 4.12 & 156 \\
\hline Lundquist number, $S\left(10^{6}\right)$ & $0.015(1.5)^{(a)}$ & 0.01 & 7.93 & 242 & 487. \\
\hline Average Plasma Current, $I_{*}(M A)$ & 0.08 & 0.06 & 2. & 10.2 & 17.8 \\
\hline Drive Frequency, $f(H=)$ & 5000 & 2000 & $2 \times 3$ & 60. & 25 \\
\hline Toroidal-flux awing $\delta \phi / \phi_{0}$ & 0.035 & 0.05 & 0.035 & 0.035 & 0.035 \\
\hline Current swing, $\delta I_{\phi} / I_{\phi}(\%)$ & & 7 & 6.4 & 2.4 & 1.6 \\
\hline$\Theta$ Variation & & $1.5-1.9$ & $1.39-1.60$ & $1.47-1.58$ & $1.50-1.62$ \\
\hline F Veriation & & $-0.1--0.5$ & $-0.03--0.36$ & $-0.04--0.20$ & $-0.03--0.17$ \\
\hline Plauma discipation. $P_{n}$ & 2.8 & 3. & 14.0 & 23.3 & 286 \\
\hline \multicolumn{6}{|l|}{ Toroidal Circuit $\left(\mathrm{M} / \mathrm{U}^{\prime}\right)$} \\
\hline Plasma Poynting power. $P_{P}^{*}$ & & & 1.385 & 2.826 .8 & 3.960 .0 \\
\hline First-wall discipation. $P_{F W}$ & & & $30.7(0.0)$ & 0.0 & 0.0 \\
\hline Blanket discipation, $P_{B}$ & & & $0.6(0.4)$ & 1.6 & 0.0 \\
\hline \multicolumn{6}{|l|}{ Poloidal Circuit $\left(M U^{\prime}\right)$ : } \\
\hline Piar mu Poynting power. $P_{p}$ & & & 41.2 & 114.9 & 247.3 \\
\hline First-wall dissipation, $P_{F W}$ & & & $6.2(0.0)$ & 0.0 & 0.0 \\
\hline Blantiat dissipation. $P_{B}$ & & & $2.8(1.6)$ & 17.7 & 0.2 \\
\hline \multicolumn{6}{|l|}{ Terminal Reactive Power, $P \cdot(M / V A)$} \\
\hline $\mathrm{OH}$ coils & & & $390.8(240.8)$ & 3.3 & 102.0 \\
\hline TF coils & & & $253.3(187.9)$ & 9443 & 1.413 .2 \\
\hline EF coils & & & $941.2(921.9)$ & 67.2 & $\sim 0^{(b)}$ \\
\hline Trim coils & & & -. & 817.6 & 147.2 \\
\hline \multicolumn{6}{|l|}{ Coal Diseipation, $P_{1}\left(M U^{*}\right)$} \\
\hline $\mathrm{OH}$ coils & & & $0.1(0.0)$ & 0.0 & 0.2 \\
\hline TF coils & & & $1.5(1.3)$ & 106 & 35.7 \\
\hline EF coils & & & $1.1(1.1)$ & 54.6 & $\sim 0^{(b)}$ \\
\hline Trim coils & & & - & 26.3 & 25 \\
\hline \multicolumn{6}{|l|}{ Real (lost) Terminal Power. $F_{1}^{T}\left(M W^{r}\right)$} \\
\hline $\mathrm{OH}$ coils & & & $40.1(3.1)$ & 0.1 & 12 \\
\hline TF coils & & & $193(117)$ & 4.2 & 62.5 \\
\hline EF coils & & & $-26(34)$ & 52.6 & $-0^{(b)}$ \\
\hline Trim coils & & & -- & 37.3 & 35 \\
\hline TF-coil de power, $P_{T F}^{5 S}\left(M U^{\prime}\right)$ & & & $10(1.0)$ & 8.8 & 291 \\
\hline EF-coil de pomer. P $P_{E}^{S}(M U)$ & & & $11(11)$ & 526 & $-0^{(b)}$ \\
\hline Power-eupply diuepstion. $\operatorname{PPS}\left(M \mathcal{H}^{\prime}\right)$ (r) & & & $159(135)$ & 18.3 & 166 \\
\hline Cur ent-drive pawer. $P_{r} \cdot(M H)$ & & 7 & $706(29 \varepsilon)$ & 91.0 & 546 \\
\hline Cumme-dive eflicienc), $I_{\theta} / P_{c}, D(A / W)$ ' & (ब) & 0.0086 & $0.028(0067)$ & 0.11 & 0.33 \\
\hline
\end{tabular}

\footnotetext{
(a) For the ZT.P parameters. OFCD is not possible The values in perenthesis indicate the minimium change in loop

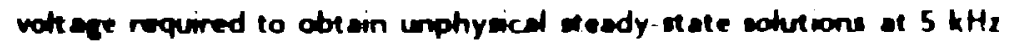

(b) Superconduction EF coils are uned

(c) Aneumet the pomet muppluet we $99 \%$ fficient

(d) This efficiency in based on total powner consumed in the system exchuding steady ste coil bases An equivalent

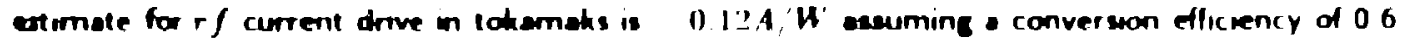


model indicstes that this shell model is least accurate at low coil aspect ratio (the $\mathrm{OH}$-coil self-inductonce is overatimated by - factor of two); an accuracy of better than $20 \%$ is obtained for the higher supect-ratio circuit elements. which account for most of the power dissipation. The algorithms described in Sec. II error conservatively and are of uflicient accuracy for eatimating the $O F C D$ resctive power ond current-drive efliciency.

The current-drive algorithms were applied to the iforementioned apectrum of air-core RFPs, and the results we summarized in Table $I$. No steady-state solutions were btained for ZT.P because the upper and lower bounds on :he oxillation period overlap. The current-drive operating vindow for ZT.P can be opened if $\tau_{R}$ is increased by at east 100 ot a driver frequency of $5 \mathrm{kHz}$; the $5-\mathrm{kHz}$ driver requency was chosen to abtain an ascillation period that is freater than $r_{T}$ and therefore connot be increased further. $A$ large inciease in $\tau_{R}$ for ZT.P con be obtained only by :hanging the plasme resistance by. for example, decreasing he plasma charge to $Z_{\text {eff }}=1$ and increasing the plasma emperature to $T_{c}=2 \mathrm{kel}$, neither of which ore posaible. tccompanying a change in the plasmo resistance is a change $n$ T as is illustrated in Table I for a two order-of-magnitude lecrease in the plasma resistance and, hence, loop voltage. The MHD tearing-time constraint on the oscillation period is riolsted for such a low loop voltage, and current drive would ot be possible.

he ZT-40M parameters and OFCD results for the xperiment in which a $5 \%$ increase in poloidal flux was bserved $^{3}$ ore included in Table $I$. The $Z T-40 \mathrm{M}$ results ore 1 - tetotively low $(60 \mathrm{kA})$ current becouse higher (180-200 A) current experiments suffered from enhanced plasms-wall iteractions (PWI) which increased the plasmo resistance nd mezated any $O^{-} C D$ effect. A divertor that fixes re separatrix during OFCD could minimize PVI effects. imulation of ZT-40M with the algorithms of Sec. II was not assible becouse $2 \mathrm{~T} 40 \mathrm{M}$ is an iron-core device and requires different circuit model, but has been simulated in Ret. 5 .

the mext lerger RFP simulated is ZTH operatec at $1=2 M A$. Driver frequencies which atisfy the period snstraints we in the range of $100-200 \mathrm{Hx}$. A drive frequency $1200 \mathrm{~Hz}$ was chosen becouse $100 \mathrm{~Hz}$ produced aufliciently re ascillations to lose reveral at a normalized coroidalux ming of $\phi \phi / \phi_{0}=0.035$ used for all devices simulated. everaed ready-atate solutiona were abtained at $100 \mathrm{~Hz}$ * 0.065 : $\delta . / \phi_{n}=0.100$ and at $200 \mathrm{~Hz}$ for 0.030

$\delta \phi / \phi_{n}=0.115$. The upper bound on $\delta \phi / \phi_{n}$ at both equencies is an by the maximum accillotion in coroidal Jx. The lomer bound is at by the upper bound on 1. killations and. hence. $\theta$. which results in - lons of revers al receuse odherence to on $F$. $\theta$ curve is required

he continuous ines in ZTH mould disaipate $37 \mathrm{MW}$ and count: for over half of the entire current-drive pownt. Is is indicated in Table I. Toroidal and poloidal gaps in the liner reduce the liner dissipation to $30 \mathrm{~W}$. The liner gaps must hold of $\mathrm{lmm}$ toroidal and poloidal electric fields of 0.06 and $0.11 \mathrm{l} / \mathrm{m}$, respectively. The continunus liner also souses substantially larger resctive powers in the $\mathrm{OH}$ and TF coils compared to a liner with gaps. The increased $O H$. coil flux swing couples to the EF coils and overdrives the EF coils so that power must be extracted from the EF coils to maintain steady state. Operation either at higiner values of $\delta \phi / \phi_{0}$. which reaults in tomer omplitude plasms-current accillations, or with a liner with gaps would elimirate the EF-coil overdrive.

The current and voltage wave forms for ZTH with a continuous liner are shown in Fig. 4. The largest amplitude current oscillation occurs in the TF coils, in which the current slso changes direction: the toroidal field at the plasma. however, does not change sign because poloidal currents in the liner and ahell maintsin a reversed field. A larger value for $\delta \phi / \phi_{0}$ eliminates the slternating direction of the TF-coil curtent. The shell currents are larger than the liner currents even theugh the shell has gaps becouse the shell is relatively thick $(10 \mathrm{rnm})$ and has a non-negligible inductance and a resis.ance that maximizes the induced current The TF-coil voltage has o large phase ahift $\left(\sim 73^{\circ}\right)$ relative to the plasma voltage, $l_{0}$. becouse of the relatively large space between the TF coils and the plosms surface.

The lost two RFP devices considered, FTF and TITAN. II, have gaps in the first wall: - 120-MW power wovings results for TITAN-iI. The drive frequencies for FTF and TITAN-II ore low becouse of the lower loop voltege The mean values of $F$ ore lower than in ZT-P and ZTH (.0 I versus -0.2 , respectively) to minimize the steady-stote $: F$ ccil disuipation. Both designz use an EF trim coil to track the equilibrium in order to reduce the resctive power: 7 GVA reactive power rediction results for TITAN-II. The FTF design has a larger blanket dissipation compared to TITAN. II because diflerent blanket moterials result in a $10^{n}$ smaller blonket resistivity for FTF.

\section{N. CONCLUSIONS}

In progreasing from present experiments to the commercial resctior, RFP. become lerger and require more plasme current to produce increased temperature and confinement time. . I decreased loup voltage Associated with increased plasms curront is onhenced PWI which may necessitate imultareous divertor operation with OFCD The currentdrive Afliciency mpirically scales os $I_{*} / P_{(n)}$ a $\left(2 l_{\beta}\right)$ ' which implies that current-drive experiments ahould become

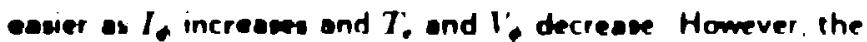
maximal current-drive dliciency of - $\boldsymbol{A}, \boldsymbol{H}$ is echievable only in the reactor regime through the ellicient managemen: of the large reactive powers associoted with OFCC The primary means to manaze this power is through the uxe of 

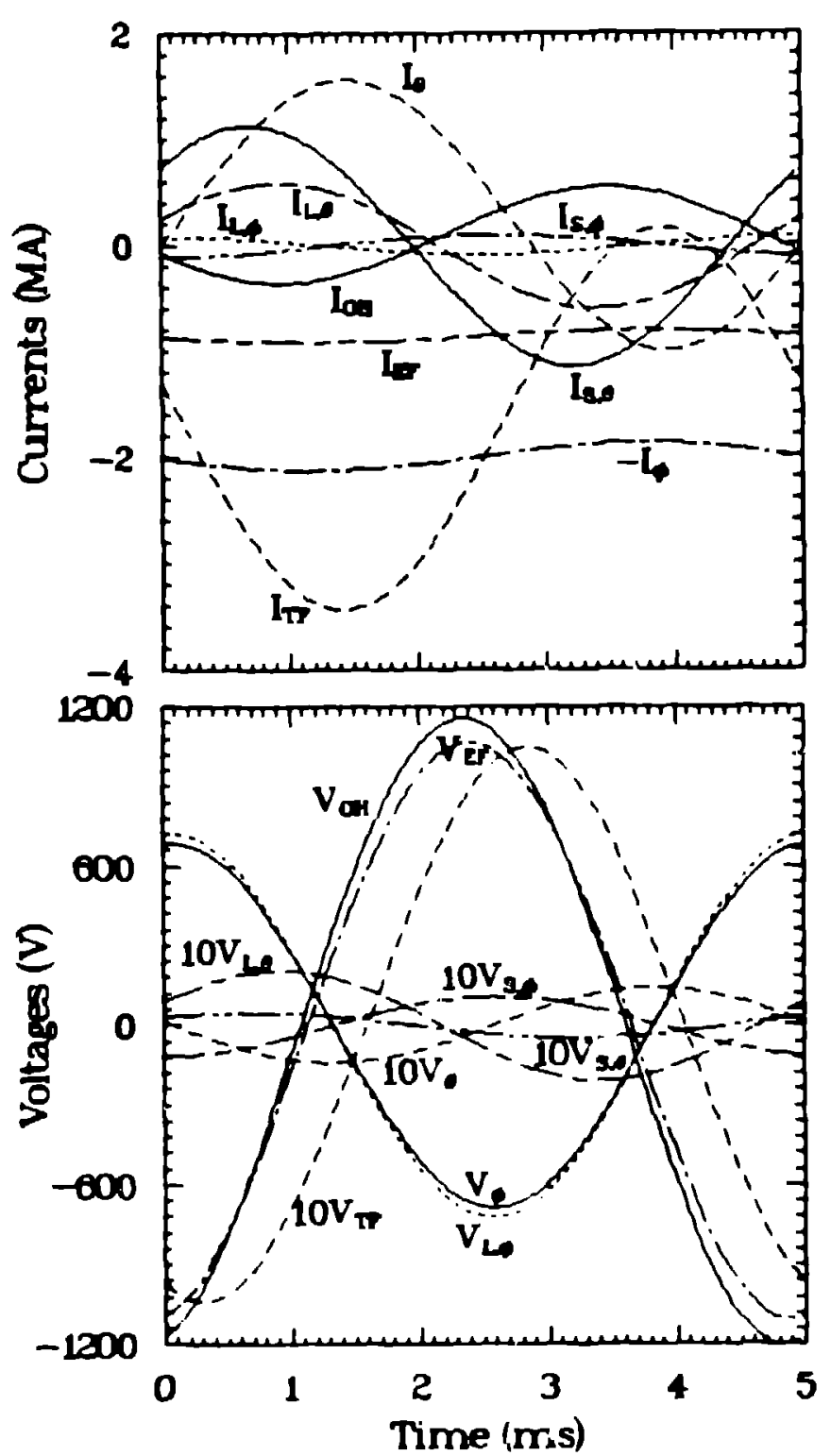

Figure 4. The current and yoltage wave form for ZTH with - continuous liner at a driver frequency of $200 \mathrm{~Hz}$.

poloidal and toroidal electrical gapt designed into structures. wch as the firat wall;liner, in which OFCD induces currents. inmulating saps, howner. creste problems anociated with field errork, vacuum lacks. and nuutron damege. A wecond pown-menezemont technique wive in the cave of a coil ext with emell emplitude accillations about large nteady-etate currente. A meller reactive pown is obtained by dividine this coil ax into a m (trim coils) devoted to the current aceillotion and a accond at to produce the cteady-itate curvent. The final powr-manegement technique requires the une of high-Q power eupplies. Even for Qrs $=100$ power mpplies, which ere commercially available. the powerupply disipation is $30 \%$ of the lotel current-drive pomer for TITAN-II The dewlopmemt of $ค$ QPs $=1,000$ power eupply beend on room-temperoture euperconductors would incrense the TITAN-II currom-drive Allicienty to $\left\{A, W^{\prime}\right.$ The rewults presented herein demonatrate the potential of OFCD as an efficient method to surtain - steady-state plasma current in RFP rastors. The unambiguous experimental demonstration of OFCD. lowever, awaits larger devices (e.C. ZTH) capable of higher current and temperature operation and lower loop volteges than ere presently possible.

\section{REFERENCES}

1. J. B. TAYLOR, "Reloxation of Toroidal Plasms and Generation of Reverned Magnetic Field," Phys. Ret. Lett. 33 (1974) 1139.

2. J. B. TAYLOR, "Relaxation and Magnetic Reconnection in Plaems." Phys. Rev. Lett. 50 (1986) 741.

3. M. K. BEVIR and J. W. GRAY, "Relaxation, Flux Consumption and Quagi Steady Stote Pincties." LA-8944C Los Alamos National Laboratory (1982).

4. K. F. SCHOENBERG. R. F. GRIBBLE, and D. A BAKER. J. Appl. Phys. 80 (1984). 2519.

5. K. F. SCHOENBERG ef al.. "Oxcillating Field Current Drive Experiments in a Reversed Field Pinch," Phys. Fluido 31 (1988), 2205

6. K. F. SCHOENBERG. It., "ZT.P: An Advanced Air Core Reverned Field Pineh Prototype." LA-10593-MS Los Alamos National Loboratory (1986).

7. P. THULLEN and K. F. SCHOENBERG (Eds.). "ZT-H Reversed-Field Pinch Experiment Technical Proposal," LA-UR-942602 Los Alamos National Laboratory (1984).

8. The TITAN Reseerch Group. "The TITAN Reversed. Field Pinch Reacior Seudy-The Final Report," UCLA-PPG-1200 Uri:userity of Caifornia-Los Angeles. GA Technologies. Inc.. Los Alomos Notional Laboratory. and Renseleer Polytechnic Instifute (to be published 1988)

9. E. J. CARAMANA, R. A. NEBEL, and D. D. SCHNACK. "Nonlimar. Single-Helicity Moznetic Reconnection in the Reveread-Field Pinch," Phys. Flusds 20 (1983) 1305.

10. B. B. KADOMTSEV. "On Electron Heat Conductivity in Tokamaks." Fiz. Plasmy (USSR) 1 (1975) 938.

11 D. D. SCHNACK. E. J. CARAMANA, and R. A. NEBEL. "Thren-Dimenaional Megnetohydrodynamic Studies of the Rovereed-Field Pinch." Phys. Fluids 28 (1905) 321.

12. R. L. HAGENSON. 1 l.. "Compar Reversed-Field Pinch Reactors (CRFPR): Preliminery Engineering Conviderations." LA-10200MS Los Alomos National Loboratory (1994).

13. C.G. BATHKE. is l.. "Conceptual Deaign of Reverned-Field Pinch Funion Nevtron Source." paper preaented at International Symposium on Fusion Nuclear Technology (ISFNT). Tohyo. Japan (April 10-15. 1908)

14. R. J THOME and J M TARRH, MIHI) and Fumm! Magnets Field and Fower Deagn (:mcepts. John Wiley A Soni. NY (1902).

I5 V D. SHAFRANOV. "Plasmo Equlibrium in a Magnetic Field." Rerneuse of Planma Physurn. Conoultant Bureau, Now Yoth, 2 (1066). 103 